\title{
COLOR STABILITY OF A NANOFILL COMPOSITE: EFFECT OF DIFFERENT IMMERSION MEDIA
}

\author{
Silvia Terra FONTES'1, María Raquel FERNÁNDEZ ${ }^{1}$, Claudia Modena de MOURA², Sônia Saeger MEIRELES ${ }^{3}$
}

\author{
1- DDS, MS, PhD student, Department of Operative Dentistry, Dental School, Federal University of Pelotas, Pelotas, RS, Brazil. \\ 2- DDS, Private Practice, Porto Alegre, RS, Brazil. \\ 3- DDS, MS, PhD, Adjunct Professor, Department of Operative Dentistry, Federal University of Paraíba, João Pessoa, PB, Brazil.
}

Corresponding address: Sônia Saeger Meireles - Avenida Umbuzeiro, 755 apt 901, Bairro: Manaíra - 58038-180, João Pessoa - PB - Brazil - Phone: +558332167250 - e-mail: soniasaeger@hotmail.com

Received: August 13, 2008 - Modification: May 18, 2009 - Accepted: November 09, 2008

\begin{abstract}
$O$

bjective: The aim of this in vitro study was to evaluate the color stability of a nanofill composite resin (Filtek Z350) in different immersion media. Materials and methods: Twelve resin-based composite specimens were prepared using a silicon cylindrical mold measuring $\cong 1 \mathrm{~mm}$ of thickness and $\cong 10 \mathrm{~mm}$ of diameter. Specimens were light-cured for $40 \mathrm{~s}$ from both sides using a LED Radii at $1400 \mathrm{~mW} / \mathrm{cm}^{2}$ and were randomized into 4 groups $(\mathrm{n}=3)$ according to immersion media: coffee, yerba mate, grape juice or water (control solution). A digital spectrophotometer was used to evaluate the color changes at baseline and at 1-week after immersion in each solution. Specimens were stored in the different staining media for $4 \mathrm{~h} /$ day during 1 week. The color differences $(\Delta \mathrm{E})$ were analyzed by paired t-test and one-way ANOVA with complementary Tukey test $(\mathrm{p}<0.05)$. Results: After 1 -week of immersion, a perceptive color change for the group stored in the grape juice compared to baseline $(p=0.008)$ was observed. Coffee and yerba mate did not show any color changes visible for the human eyes or significantly different from the control group ( $p>0.05)$ Conclusions: The findings of the present study suggest that the tested nanofill resin-based composite was susceptible to staining by substances present in the grape juice.
\end{abstract}

Key words: Composite resins. Nanoparticles. Staining.

\section{INTRODUCTION}

The use of composite resins has become an important reality in restorative dentistry. Due to improvements in both physicomechanical and esthetic properties, composite resins are presently among the most popular esthetic restorative materials in dental clinical practice. This fact, allied to the decline of caries incidence and severity, has directed the clinician's attention to conservative and non-invasive treatments. Manufacturers have introduced different shades for restorative materials, capable of fulfilling all the requirements for environment light sensitivity, depth or cure, color match and stability ${ }^{15}$.

The success of dental restorations depends, among other issues, on compressive, diametral tensile and flexural strengths, wear and fracture resistance and polish retention ${ }^{13}$. Furthermore, aesthetics restorative materials should mimic the appearance of natural tooth, and this fact is directly related to the material's color match and color stability ${ }^{3}$. However, it is known that restorative composites have a tendency to discoloring when exposed to the oral environment ${ }^{18}$. Despite this, color stability between composite resin and tooth can be affected by absorption of pigments or by an intrinsic factor inherent to the material. It has been shown that some composite resin components may have an effect on discoloration phenomenon ${ }^{19,20}$.

Previous studies have shown that composite resins are susceptible to color instability when exposed to various staining media, especially red wine, coffee, cola, tea and whisk $^{1,2,5,14}$. Moreover, restorative material discoloration might be attributed to water sorption degree and matrix resin hydrophilicity. If a composite resin can absorb water, it can also absorb other fluids, resulting in color alteration ${ }^{2}$. Additionally, filler particle size and distribution as well as resin matrix composition have been shown to play an important role in this context ${ }^{17}$. The photoinitiator system can not only influence the polymerization characteristics, but also have impact on the composite color stability 9 . Some studies have reported high surface roughness of composites, even after finishing, due to irregularly arranged inorganic filler particles, which could result in easier staining over time $^{6,14}$.

Tooth surface discoloration by the deposition of extrinsic stains is currently treated by professional cleaning with scaling and polishing ${ }^{10}$. However, intrinsic stains on 
composite restorations cannot be removed superficially, and might demand restoration replacement. Both science and technology of composite dental restorative materials have advanced considerably ${ }^{14,16}$. The resin-based materials that have been on the market have improved their physical properties due to new filling concepts and matrix changes. Strength and esthetic properties of the resin-based nanocomposites should allow the clinician to use it for both anterior and posterior restorations alike ${ }^{13}$.

The aim of this in vitro study was to evaluate the color stability of a nanofill restorative composite in different immersion media. The null hypothesis tested was that staining solutions have no effect on discoloration susceptibility of the resin-based material.

\section{MATERIAL AND METHODS}

Color stability of a new-generation direct restorative composite resin (Filtek Z350 A2E, 3M ESPE, St. Paul, MN, USA) was tested in four immersion media: coffee, yerba mate, grape juice and distilled water. Twelve discs, with \pm 1 $\mathrm{mm}$ of thickness and $\pm 10 \mathrm{~mm}$ of diameter, were prepared using a silicon cylindrical mold. After inserting the material into the mold, a polyester strip was pressed onto the mold surface with a glass plate in order to obtain a flat surface without bubble formation. Discs were light-cured for $40 \mathrm{~s}$ from both sides using a LED source (Radii, SDI, Bayswater, VC, Australia; $1,400 \mathrm{~mW} / \mathrm{cm}^{2}$ power density) fixed at a distance of $1 \mathrm{~mm}$ from each specimen. The light-activation time was performed according to manufacturer's recommendations. The cured specimens were removed from the mold and polished with wet 600- and 1200-grit siliconcarbide ( $\mathrm{SiC}$ ) paper for $60 \mathrm{~s}$ to standardize the resin surfaces. The disc thicknesses were measured with a digital caliper (DC 500-144B, Mitutoyo, Santo Amaro, SP, Brazil).

Specimens were randomized to 4 groups according to storage solution ( $\mathrm{n}=3)$ : (1) coffee, (2) yerba mate, (3) grape juice and, (4) distilled water (control group). Solution's pH was verified by a pHmeter (PM 608 Plus, Analion, Ribeirão Preto, SP, Brazil), which indicated no changes during the period of treatment. All the procedures were carried out by the same operator at room temperature of $23^{\circ} \mathrm{C}$ and relative humidity of $50 \%$. Test groups and their respective $\mathrm{pHs}$ are summarized in Figure 1.

After immersion in distilled water for $24 \mathrm{~h}$, color values were recorded using a digital spectrophotometer (Vita
Easyshade, Vita Zahnfabrik, Bad Säckingen, Germany). Color measurements were performed by positioning the specimens on a white background to prevent potential absorption effects on any of colors parameters. The color data was recorded before (baseline) and 1-week after storage in the different liquids. Three specimens were kept $4 \mathrm{~h} /$ day during 1 week in each one of the four different immersion media and these solutions were daily renewed. After the immersion period, the specimens were washed and stored in distilled water.

The spectrophotometer measures the teeth color based on the CIEL* $\mathrm{a}^{*} \mathrm{~b}^{*}$ color space system which allowing the determination of color in the three-dimensional space ${ }^{4}$. The $\mathrm{L}^{*}$ represents the value (lightness or darkness). The $\mathrm{a}^{*}$ value is a measure of redness (positive $\mathrm{a}^{*}$ ) or greenness (negative $\left.a^{*}\right)$. The $b^{*}$ value is a measure of yellowness (positive $b^{*}$ ) or blueness (negative $\mathrm{b}^{*}$ ). The color difference $(\Delta \mathrm{E})$ between the color coordinates was calculated by applying the formula $\Delta \mathrm{E}^{*}=\left[\left(\Delta \mathrm{L}^{*}\right)^{2}+\left(\Delta \mathrm{a}^{*}\right)^{2}+\left(\Delta \mathrm{b}^{*}\right)^{2}\right]^{1 / 2}$ in order to compare values before and after the storage treatment. Three measurements were done with the active point of the spectrophotometer in the center of each specimen, and thus, the instrument automatically averaged the three readings for each specimen, which were used for overall data analysis. The obtained data were tabulated and subjected for statistical analysis (Sigmastat 3.01, Systat, USA) using the paired ttest, one-way ANOVA and Tukey's test $(\mathrm{p}<0.05)$.

\section{RESULTS}

After 1-week of immersion in coffee, yerba mate or water, specimens did not show significant differences for $\Delta \mathrm{E}$ values than the baseline ( $\mathrm{p}>0.05)$. However, the group stored in grape juice showed a statistically significant increase of the $\Delta \mathrm{E}$ values than the baseline $(\mathrm{p}=0.008)$ (Table 1). After immersion for 1 week, significant differences in $\Delta \mathrm{E}$ values were observed between grape juice $\mathrm{x}$ coffee $(p=0.002)$ and, between grape juice $x$ yerba mate $(p=0.001)$. Differences in $\Delta \mathrm{E}$ values between coffee $\mathrm{x}$ yerba mate were not significant $(\mathrm{p}>0.05)$.

\begin{tabular}{|l|l|l|l|}
\hline Storage solution & Batch \# & pH & Manufacturer \\
\hline Coffee & 52691210 & 4.9 & Nestlé Ltda., São Paulo, SP, Brazil \\
Yerba mate & $09 / 060$ & 5.9 & Madrugada Alimentos Ltda., Venâncio Aires, RS, Brazil \\
Grape juice & $049 / 60$ & 2.8 & Vinícola Garibaldi Ltda., Garibaldi, RS, Brazil \\
Distilled water & & 5.6 & CDC-Bio, UFPel ${ }^{*}$, Pelotas, RS, Brazil \\
\hline
\end{tabular}

FIGURE 1- Type, batch number, $\mathrm{pH}$ and manufacturers of the immersion solutions

*Development and Control Center Biomaterials, Dental School, Federal University of Pelotas 
TABLE 1- Color means, standard deviations (SD) and color difference $(\Delta \mathrm{E})$ in the two evaluation periods for the specimens immersed in the different storage solutions

\section{Evaluation period}

Spectrophotometer evaluation Means ( \pm SD)

\section{Coffee Yerba mate Grape juice Water}

Baseline

(Distilled water immersion)

$6.5( \pm 1.2)$

$5.9( \pm 1.3)$

$6.3( \pm 0.5)$

After 1-week of immersion

$9.1( \pm 2.5)$

$8.0( \pm 0.7)$

$17.6( \pm 1.5)$

Difference $(\Delta \mathrm{E})$

$2.6( \pm 3.5)$

$2.1( \pm 1.6)$

$11.2( \pm 1.7)$

p-value

0.3

0.1

$0.008^{*}$

$6.5( \pm 1.6)$
$5.6( \pm 2.1)$
$0.9( \pm 0.7)$
0.2

* Difference statistically significant between groups $(p<0.05)$.

\section{DISCUSSION}

As tooth-colored restorative dental materials are continuously exposed to saliva, beverages and food stains in the oral environment, it is important to determine their susceptibility to color change. To ensure restorations' imperceptibility both intrinsic color stability and staining resistance over a long period in the oral environment are necessary ${ }^{2}$. Although clinical studies require long-term evaluation periods to achieve results, several laboratory tests have been used in order to simulate and accelerate the discoloration, simulating oral aging conditions ${ }^{9}$. For this in vitro study, the color of composite resin specimens was measured after two different immersion times: at baseline (immersion in distilled water for $24 \mathrm{~h}$ ) and, after 1-week immersion in four different staining solutions.

A recent study ${ }^{12}$ showed that an adequate evaluation of color stability in tooth restoration can be carried out by either visual assessment with shade guides or use of a digital spectrophotometer. Considering the color as a complex phenomenon, several factors such as lighting conditions, translucency, opacity, light scattering and human eye, may influence the overall perception of tooth color ${ }^{11}$. To eliminate potential subjective errors in color assessment, the present study used a spectrophotometer for color measurements. Thus, it was possible to compare the color change after staining immersion treatment by the $\Delta \mathrm{E}$ parameter of CIEL*a*b* system ${ }^{4}$. According to individual ability of human eye to appreciate differences in colors, three different intervals were used to distinguish changes in color values: $\Delta \mathrm{E}<1$ - imperceptible by the human eye; $1.0<\Delta \mathrm{E}<3.3-$ considerate appreciate only for skilled person, both clinically acceptable and, $\Delta \mathrm{E}>3.3$ - easily observed, these color changes values are not clinically acceptable ${ }^{1,19}$. In this way, the restorations might be considered clinically acceptable once it is not necessary to replace them when $\Delta \mathrm{E}$ is less than 3.3 .

According to the manufacturer's description, the composite resin used in this study is a direct restorative nanocomposite, light-cured, and suitable to be used for both anterior and posterior restorations. Monomers like bisphenol
A diglycidyl methacrylate (Bis-GMA), ethoxylated bisphenol A glycol dimethacrylate (Bis-EMA), urethane dimethacrylate (UTDMA) and a small portion of a hydrophilic monomer triethylene glycol dimethacrylate (TEGDMA) are also present in its composition. The color change may be easily related to the nature of this resin matrix. The presence of low TEGDMA content may limit water uptake and, consequently, color variations induced by the absorption of the staining solution ${ }^{19}$. Likewise, the filler content seems to play an important role in composite color stability $^{16,17}$. A previous study showed that the filler particle size and distribution seem to be directly correlated to optical properties and that nanofiller particles provide low visual opacity in non-pigmented dental composites ${ }^{13}$. Moreover, a smaller filler size might contribute to decrease staining and enhance esthetic appearance ${ }^{19}$.

Although developments in filler technology have led to significant improvements regarding filler size, low wear and high resistance against degradation of resin materials, the present study showed that immersion in grape juice caused a high color change in the specimens after the staining treatment with a difference in $\Delta \mathrm{E}$ values of $11.2( \pm 1.7)$. These results indicate that this composite staining will be easily perceptible and thus clinically unacceptable. It is likely that the lower $\mathrm{pH}$ of the grape juice affected the composite resin surface, increasing pigment absorption ${ }^{6,14}$. However, few studies have evaluated the association between $\mathrm{pH}$ variations and staining ${ }^{1,7}$.

Previous studies have shown that the greatest color change was observed when the materials were immersed in red wine ${ }^{2,5,14}$. However, it was not explained whether staining was caused by the alcohol or by the presence of pigments in the wine. In order to eliminate these variations, grape juice was used in the present study as an alternative beverage. Furthermore, composite resins were also exposed to yerba mate because there is a high intake of this beverage in Southern Brazil. As the solutions tested in this study do not represent all substances to which restorative materials may be exposed in the oral environment, additional studies are necessary to investigate the color stability of composite resin-based materials. 


\section{CONCLUSION}

Within the limitations of this study, it may be concluded that grape juice caused perceptible color changes on the composite resin, while coffee and yerba mate resulted in no perceptible color change. As the composite resin tested in this study was susceptible to staining only by grape juice, the null hypothesis was partially rejected.

\section{REFERENCES}

1- Abu-Bakr N, Han L, Okamoto A, Iwaku M. Color stability of compomer after immersion in various media. J Esthet Dent. 2000;12(5):258-63.

2- Bagheri R, Burrow MF, Tyas M. Influence of food-simulating solutions and surface finish on susceptibility to staining of aesthetic restorative materials. J Dent. 2005;33(5):389-98.

3- Choi MS, Lee YK, Lim BS, Rhee SH, Yang HC. Changes in surface characteristics of dental resin composites after polishing. J Mater Sci Mater Med. 2005;16(4):347-53.

4- Commission Internationale De L'Eclairage. Recommendations on uniform colour spaces, colour difference equations and psychometric colour terms. Paris: Bureau Central de la CIE; 1978.

5- Ertas E, Guler AU, Yucel AC, Koprulu H, Guler E. Color stability of resin composites after immersion in different drinks. Dent Mater J. 2006;25(2):371-6.

6- Guler AU, Kurt S, Kulunk T. Effects of various finishing procedures on the staining of provisional restorative materials. J Prosthet Dent 2005;93(5):453-8.

7- Imparato JC, Garcia A, Bonifacio CC, Scheidt L, Raggio DP, Mendes FM, et al. Color stability of esthetic ion-releasing restorative materials subjected to $\mathrm{pH}$ variations. J Dent Child. 2007;74(3):189-93.

8- International Organization for Standartization. ISO 4049 - dentistry polimer-based filling, restorative and luting materials. 3rd ed. Geneva: The Organization; 2000.

9- Janda R, Roulet JF, Kaminsky M, Steffin G, Latta M. Color stability of resin matrix restorative materials as a function of the method of light activation. Eur J Oral Sci. 2004;112(3):280-5.

10- Joiner A. The bleaching of teeth: a review of the literature. J Dent. 2006;34(7):412-9.

11- Joiner A. Tooth colour: a review of the literature. J Dent. 2004;32(Suppl $1): 3-12$.

12- Meireles SS, Demarco FF, Santos Ida S, Dumith SC, Della Bona A Validation and reliability of visual assessment with a shade guide for toothcolor classification. Oper Dent. 2008;33(2):121-6.

13- Mitra SB, Wu D, Holmes BN. An application of nanotechnology in advanced dental materials. J Am Dent Assoc. 2003;134(10):1382-90.

14- Patel SB, Gordan VV, Barrett AA, Shen C. The effect of surface finishing and storage solutions on the color stability of resin-based composites. J Am Dent Assoc. 2004;135(5):587-94.

15- Puckett AD, Fitchie JG, Kirk PC, Gamblin J. Direct composite restorative materials. Dent Clin North Am. 2007;51(3):659-75.

16-Rodrigues SA Jr, Ferracane JL, Della Bona A. Flexural strength and Weibull analysis of a microhybrid and a nanofill composite evaluated by 3- and 4-point bending tests. Dent Mater. 2008;24(3):426-31.
17- Rodrigues SA Jr, Scherrer SS, Ferracane JL, Della Bona A. Microstructural characterization and fracture behavior of a microhybrid and a nanofill composite. Dent Mater. 2008;24(9):1281-8.

18- Uchida H, Vaidyanathan J, Viswanadhan T, Vaidyanathan TK. Color stability of dental composites as a function of shade. J Prosthet Dent. 1998;79(4):372-7.

19- Vichi A, Ferrari M, Davidson CL. Color and opacity variations in three different resin-based composite products after water aging. Dent Mater. 2004;20(6):530-4.

20- Watts A, Addy M. Tooth discolouration and staining: a review of the literature. Br Dent J. 2001;190(6):309-16. 